\title{
Mixed colloids and acute kidney injury: a case of selection bias?
}

\author{
AB Johan Groeneveld ${ }^{1}$, Roberta J Navickis ${ }^{2}$ and Mahlon M Wilkes ${ }^{2 *}$ \\ See related research by Frenette et al., http://ccforum.com/content/18/6/602
}

In a previous issue of Critical Care, Frenette and colleagues [1] described a retrospective study of 984 cardiac surgery patients receiving mixed colloids, including hydroxyethyl starch (HES) $130 / 0.4$ in $82 \%$ or HES 200 / 0.5 in $43 \%$. In $25 \%$ or more of the patients, both HES solutions were used. A small minority (16\%) received 5\% or $25 \%$ albumin. An association was observed between albumin exposure and acute kidney injury (AKI).

Much essential information is not provided, including what colloids were administered, why, and when. How many patients received 5\% albumin? 25\% albumin? How often was albumin co-administered with HES 130/0.4? With HES 200/0.5? With both? In what co-administered doses? How much of each colloid was used for extracorporeal circuit priming? For volume expansion? How much albumin was used to correct hypoalbuminemia? What was the temporal relationship between albumin infusion and AKI development?
No serum albumin levels are reported. Yet preoperative hypoalbuminemia is a potent independent risk factor for renal failure in cardiac surgery patients (adjusted odds ratio $2.0,95 \%$ confidence interval 1.3 to 3.2) [2]. A reported $15 \%$ of patients come to cardiac surgery with severe hypoalbuminemia (less than $25 \mathrm{~g} / \mathrm{L}$ serum albu$\mathrm{min})$, and the majority of those (58\%) undergo elective procedures [2].

Albumin is typically reserved for a small minority of the highest-risk patients [3,4]. That practice may explain this study. The significantly lower HES 200/0.5 doses co-administered with albumin in the propensitymatched population suggest that albumin was substituted to mitigate the increased AKI risk of HES 200/0.5 previously reported by this same team of investigators [5]. With obvious potential selection bias and many unanswered questions, this study needs to be interpreted with caution.

\section{Authors' response}

Josée Bouchard, Anne Julie Frenette, Stéphan Troyanov and David R Williamson

We agree with Groeneveld and colleagues that there are several unanswered questions regarding the use of albumin. Albumin administration has been associated with different outcomes depending on the type of population studied [6-9]. In the recent Albumin Italian Outcome Sepsis (ALBIOS) trial, administration of 20\% albumin did not improve prognosis by correcting hypoalbuminemia, improving hemodynamic status, or restricting the total amount of fluid administered [9]. In addition, albumin is expensive and may carry an infectious risk.

In our study, we acknowledged that we could not rule out residual confounding despite the use of a propensity

* Correspondence: mwilkes@hygeiaassociates.com

${ }^{2}$ Hygeia Associates, 17988 Brewer Road, Grass Valley, CA 95949, USA

Full list of author information is available at the end of the article score analysis and mentioned that we did not have data on serum albumin levels [1]. However, we described the timing and type of colloids administered and stated that the vast majority of the surgeries were elective. We used a propensity score analysis, which included the percentage and dose of synthetic colloids administered, to address any indication bias. However, our study does not provide a definitive answer on the administration of albumin in cardiac surgery patients. As we concluded, we believe that the safety of albumincontaining fluids on kidney function should be assessed in future cardiac surgery trials. The administration of a costly product currently associated with neutral or potentially negative outcomes in this population needs to be better delineated. 


\section{Abbreviations}

AKI: Acute kidney injury; HES: Hydroxyethyl starch.

\section{Competing interests}

$A B J G$ has received research grant funding from $B$. Braun (Melsungen, Germany) and speakers fees from B. Braun and Baxter (Deerfield, IL, USA). RJN and MMW have received unrestricted research grant support from Baxter, CSL Behring (King of Prussia, PA, USA), and Grifols (Barcelona, Spain).

\section{Authors' contributions}

All authors participated in the conceptualization and composition of the letter. All authors revised the letter and read and approved the final manuscript.

\section{Acknowledgments}

This work is solely that of the authors. No other individual or organization contributed substantially to the conception of the letter or to manuscript preparation and revision.

\section{Author details}

'Department of Intensive Care, Erasmus Medical Center, 230 Gravendijkwal, 3015 CE Rotterdam, The Netherlands. ${ }^{2}$ Hygeia Associates, 17988 Brewer Road, Grass Valley, CA 95949, USA.

\section{Published online: 30 April 2015}

\section{References}

1. Frenette AJ, Bouchard J, Bernier P, Charbonneau A, Nguyen LT, Rioux J-P, et al. Albumin administration is associated with acute kidney injury in cardiac surgery: a propensity score analysis. Crit Care. 2014;18:602.

2. Engelman DT, Adams DH, Byrne JG, Aranki SF, Collins Jr JJ, Couper GS, et al. Impact of body mass index and albumin on morbidity and mortality after cardiac surgery. J Thorac Cardiovasc Surg. 1999;118:866-73.

3. Vincent JL, Sakr Y, Reinhart K, Sprung CL, Gerlach H, Ranieri VM. Is albumin administration in the acutely ill associated with increased mortality? Results of the SOAP study. Crit Care. 2005;9:R745-54.

4. Schortgen F, Girou E, Deye N, Brochard L. The risk associated with hyperoncotic colloids in patients with shock. Intensive Care Med. 2008;34:2157-68.

5. Rioux JP, Lessard $M$, de Bortoli B, Roy $P$, Albert $M$, Verdant $C$, et al. Pentastarch $10 \%(250 \mathrm{kDa} / 0.45)$ is an independent risk factor of acute kidney injury following cardiac surgery. Crit Care Med. 2009;37:1293-8.

6. Sort P, Navasa M, Arroyo V, Aldeguer X, Planas R, Ruiz-del-Arbol L, et al. Effect of intravenous albumin on renal impairment and mortality in patients with cirrhosis and spontaneous bacterial peritonitis. N Engl J Med. 1999;341:403-9.

7. SAFE Study Investigators, Finfer S, McEvoy S, Bellomo R, McArthur C, Myburgh J, et al. Impact of albumin compared to saline on organ function and mortality of patients with severe sepsis. Intensive Care Med. 2011;37:86-96.

8. Myburgh J, Cooper DJ, Finfer S, Bellomo R, Norton R, Bishop N, et al. Saline or albumin for fluid resuscitation in patients with traumatic brain injury. N Engl J Med. 2007;357:874-84.

9. Caironi P, Tognoni G, Masson S, Fumagalli R, Pesenti A, Romero M, et al. Albumin replacement in patients with severe sepsis or septic shock. N Engl J Med. 2014;370:1412-21. 